\title{
Die gesprek oor Evangelisasie
}

\section{CJA SIMPSON}

In die afgelope dekade was daar ' $n$ hernude belangstelling in evangelisasie en veral evangelisasie-metodes. Vir baie jare het die gevestigde kerke hulle, wat hierdie aspek betref, op twee terreine toegespits: die pastoraat en die apostolaat. In die pastoraat gaan dit om die versorging van die huisgenote van die geloof in gehoorsaamheid aan die opdrag: "Pas My skape op" (Joh 21:18). Hierdie pastorale werksaamheid van die kerk het by voorbaat ' $n$ ingeboude voorkomende en genesende aspek ten opsigte van die geloofsbetrokkenheid van huisgenote van die geloof. Die doel van hierdie pastorale besorgdheid en bewoënheid was om die gelowiges in "die genade en kennis van ons Here en Verlosser, Jesus Christus" te laat toeneem (2 Pet 3:18) en hulle vir hulle dienswerk in die wêreld toe te rus (Ef $4: 12$ ). Hierdie toerusting vind plaas in die erediens tydens die prediking en in die huise tydens die huisbesoek met die verkondiging van die Woord. Hierdie verkondiging het beide ' $n$ voorkomende en genesende gestalte deurdat dit die gelowiges nie net "bou" nie, maar ook "snoei", dit wil sê die prediking het ook 'n vermanende karakter. So word die getroues bemoedig en versterk en die ontroues vermaan en berispe. Die derde aspek van die pastoraat vind sy realisering in die opsig en tug. Hierdie aktiwiteit van die kerk vind binne die vaste bane van die kerklike gesprek plaas en dien as bewarende en versorgende middel sodat alles goed en welvoeglik in die gemeente sal verloop.

Naas die "na-binne-gekeerde" pastorale arbeid van die kerk van die Here, was daar ook die opdrag van die Here Jesus: "Gaan en maak dissipels." Die bewoënheid na buite het vir 'n lang tyd sy gestalte gevind in die apostolaat, dit wil sê die gestuurdheid van die kerk. Aanvanklik was hierdie sendingwerk die liefhebbery van 'n paar entoesiaste, maar later het kerke op geordende wyse hulle sendingopdrag binne die kerklike struktuur georganiseer en het daar naas sendingaksies ook plaaslike betrokkenheid ontstaan vir die "heidene" in ons midde.

Met die toenemende sekularisasie-proses (verwerkliking) en 'n al groter wordende sinkretisme (vermenging tussen wêreld en kerk) het daar 'n "nuwe" arbeidsveld ontstaan. Dié nuwe arbeidsveld is na 
alles nie so "nuut" nie, omdat dit reeds van die begin af daar was, maar in ' $n$ groot mate sedert die bekering van Konstantyn die Grote misgekyk is. Vir baie jare is aanvaar dat die Weste "Christelik" is en dat die kerk alleen in verre ongekerstende lande ' $n$ "evangeliseren$\mathrm{de}^{\prime \prime}$ taak het, naamlik sending.

Die afgelope twee eeue en veral sedert die Aufklärung en sy gevolge op die denke van die moderne mense en die gevolglike modernisme en liberalisme, het daar 'n nuwe soort mens ontstaan. Ons kan hom as die post-Christelike mens beskryf. Hy is ' $n$ mens wat nog steeds die Christelike waardes hoog ag en hom beywer om veral die Christelike humanisme uit te bou, maar die Here Jesus Christus self verloën. Hierdie mens waarvan ons praat, wil graag die voordele van die Christendom behou, maar met die Here van die kerk wil hy niks te make hê nie.

Dit is hierdie mens wat vir die kerk ' $n$ heel nuwe arbeidsterrein skep. ' $n$ Arbeidsterrein wat weliswaar net so oud as die kerk self is, maar wat nou weer herontdek word deurdat dit sig aan die kerk opdring - ja, die kerk konfronteer deur op die kerk se drumpel sig te vertoon.

Evangelisasie is dus beide in die pastoraat sowel as die apostolaat sigbaar. Evangelisasie is "het werk der kerk om in opdracht van haar Heer zijn Evangelie bekend te maken aan de velen om haar heen, die daarvan vervreemd zijn, en hen op te roepen tot geloof en bekering"1. Maar wat word met "kerk" bedoel? Beteken dit weer eens die kerk as instituut wat bepaalde ampsdraers vir hierdie besondere diens sal afsonder, of beteken dit dat die kerk deur sy lidmate se leer en lewe en getuienis teenoor die wêreld besig sal wees met die opdrag: "Wees julle my getuies."

Na my mening moet ons wat hierdie saak betref, die volgende vertrekpunt neem om sodoende 'n sinvolle benadering te verkry: "The whole church must be mobilised to bring the whole gospel to the whole world"2.

$K$ Barth maak die interessante opmerking: 'n Kerk wat nie evangeliserend optree nie, is geen kerk meer nie en moet self eers "geëvangeliseer word"3. Wat hiermee bedoel word, is eenvoudig wat die Calvinistiese Protestantisme nog altyd die "priesterskap van die gelowiges" genoem het, maar wat in praktyk tot weinig meer as kerkbesoek, die gee van offergawes, die betrokkenheid by gemeentelike funksies en die gebruik van die sakramente verskraal het.

Evangelisasie is dus maar nie net 'n taak van die kerk nie, maar 
evangelisasie is die "kerk in aksie". En die enigste dryfveer vir hierdie getuienistaak is die evangelie van Jesus Christus se versoeningsdood.

"Evangelism can never be separated from the gospel. The gospel can never be separated from its source. The source of the gospel is the Bible. Evangelism must have a Biblical basis. The zeal for evangelism lies in the heart of God Himself. Jesus Christ is the Father's missionary to a lost world"4.

Dit gaan dus oor een saak: die uitdra van die boodskap van Jesus Christus se versoeningsdood deur elke gelowige aan 'n wêreld en sy mense wat in duisternis en onkunde leef.

Hierdie opdrag kan op baie maniere plaasvind. Ek noem 'n paar van hulle.

1. Pastorale evangelisasie. Dit is die gesprek wat die pastor met sy lidmate op huisbesoek voer. Dit is die boodskap wat dikwels vanaf die kansel weerklink. Dit is die gesprek wat die pastor met enkele rand-kerklikes en evangelievervreemdes voer wanneer hulle sy pad kruis as gevolg van huwelike wat gesluit word of probleme wat in gesinne of met nàasbestaandes van gesinne opduik.

2. Massa-evangelisasie. Wanneer 'n besondere veldtog gevoer word en ' $n$ besonder begaafde spreker of prediker 'n veldtog loods en in gesprek tree met ' $\mathrm{n}$ massa $\mathrm{d} \mathrm{m} \mathrm{v}$ dialogiese prediking.

3. Persoonlike evangelisasie, ook bekend as "persoon-tot-persoonevangelisasie". Dit is oor hierdie saak wat ons enkele aspekte wil uitlig. Na my mening vind die werklike kontak tussen kerk en wêreld hier plaas. Hier waar die lidmaat as enkeling die wêreldling as mens teenoor mens, as gelowige teenoor ongelowige, as dienskneg van Christus teenoor slaaf van die duisternis en sonde ontmoet. En hier is die persoonlike gesprek die enigste doetreffende wapen. Hier is die kerk in aksie - hier slaag die kerk in sy evangelisasiewerk of hier swyg die kerk. Hier word die mens in die wêreld deur die woord gekonfronteer en hier word menige beslissing geneem.

Die rede waarom hierdie stelling gemaak word, lê opgesluit in die feit dat hierdie "kontak" tussen kerk en wêreld die mees persoonlike, die mees intieme kontak is. Hier word Christus deur een persoon aan ' $n$ ander persoon voorgestel. Hier word die ware liefde', 
die ware bewoënheid en besorgdheid ten toon gestel en vrygestel. Hier vind die grootste voorreg plaas wat enige gelowige ooit kan ervaar - om 'n sondaar aan Christus se vergewende en versoenende genade voor te stel. Christus Jesus het self hierdie stelling gemaak: "Volg My, en Ek sal julle vissers van mense maak" (Mark 1:17).

Die Engelse woord "responsibility" stel dit so pragtig: "response" is die reaksie van die gelowige, "ability" die krag wat Christus gee.

Hierdie aktiwiteit van die lidmate, om te evangeliseer, is nie 'n losstaande persoonlike liefhebbery nie. Dit is die kerk in aksie, besig om sy werk in die wêreld op elke denkbare plek, onder elke denkbare situasie, aan elke denkbare mens te verrig.

En as dit nie gebeur nie, dan is die kerk ongehoorsaam en lui en is die kerk besig om in sy dienswerk te faal ${ }^{6}$.

\section{DIE PLEK VAN DIE GESPREK IN EVANGELISASIEWERK}

Ten spyte van al die audio-visuele hulpmiddels en al die aanverwante tegnieke wat tot die kommunikasieproses se beskikking is, is en bly die gesprek steeds die belangrikste en mees effektiewe wyse waarop die evangelie aan ander oorgedra kan word?

Die rede is dat verhoudings deur sinvolle gesprek gebou word. Deur middel van gesprek kan waarhede en begrippe aangegee word, konflik ontlont word, onbegrip uit die weg geruim word en brûe gebou word ${ }^{8}$.

Ons sien al hierdie elemente in die gesprek wat Jesus met die vrou by die put in Sigar gevoer het. (Sien Joh 4:5-41.)

Die vraag kan nou gestel word: Wat is die doel van hierdie evangelisasiegesprek? Die evangelisasiegesprek is en bly in sy wese woordbediening of die bediening van die versoening (2 Kor 5:19).

Dit moet egter baie duidelik besef word dat geen mens ' $n$ ander mens kan bekeer' nie, maar dit verhinder ons nie om so met iemand besig te wees dat ons ons gespreksgenoot of genote tot ' $n$ punt bring waar hy of sy gekonfronteer word met die keuse vir of teen Christus nie $^{10}$. Dit moet onthou word dat hierdie gesprek nie 'n dialoog tussen twee mense is wat uitloop op ' $n$ kondisionering of beïnvloeding al dan nie, maar dat die evangelisasiegesprek in wese 'n gesprek is tussen twee mense onder leiding, ja begeleiding van die Heilige Gees wat nie alleen leiding gee in die getuienistaak (wat julle sal sê nie) (Joh 16:17), maar ook leiding gee in die aanhoor van die getuienis. Die Heilige Gees sal die wêreld oortuig van sonde en 
van die waarheid (Joh 16:8) en dan kan so iemand deur die verkondiging van die Woord tot geloof kom en God aanbid (1 Kor 14:25).

\section{WAT HOORT VOLGENS DIE SKRIF TUIS IN SO 'N GESPREK?}

Die gesprek met 'n ongelowige of buitekerklike of selfs evangelievervreemde het 'n besondere doel. Hierdie doel spel Paulus uit in sy woorde: "Wat my betref broers, toe ek na julle toe gekom het om die geheimenisvolle waarheid van God aan julle te verkondig, het ek nie met hoë woorde of groot geleerdheid gekom nie. Ek het my voorgeneem om met julle oor niks anders te praat nie as oor Jesus Christus en wel oor Hom as gekruisigde (1 Kor 2:1-2).

Paulus voer dieselfde saak aan in sy brief aan die Kolossense as hy sê: dat hy "'n dienaar geword het volgens die opdrag wat God hom gegee het om sy Woord ten volle aan julle bekend te maak". Hierdie woord wat hy bekend moet stel, is die "mysterion" - die geheim van God se liefde vir sondaars. Die geheim van God se verlossingsplan. Die evangelie is die ontplooiing van die woorde van Eksodus 34:7b. Dit is die ontrafeling van hoe God die sonde straf, terwyl Hy die sondaar genadig is. Dit is die ontvouing van hoe God die ongeregtigheid straf en uitroei en tegelyk die oortreder red en verlos. Hierdie geheim som Paulus op in 2 Kor 5:21 as hy sê: God het Hom (Christus) wat sonder sonde was, in ons plek as sondaar behandel, sodat ons deur ons eenheid met Christus deur God vrygespreek kon wees.

Dit gaan dus oor 'n paar sake:

1. Ons moet weet wat die doel $l^{11}$ van die gesprek is. Die gelowige is instrumentee $\mathrm{l}$ - hy is instrument in die hand van die Heilige Gees om iemand wat nie weet nie, te vertel. Hy is dus 'n getuie van die verlossende genade van God. Getuie nie op grond van wat hy ervaar het nie, maar getuie van wat hy weet waar is, ook in sy eie lewe waar geword het en waarvan hy seker is omdat Christus dit vir hom gegee het (Joh 5:24). So is die doel van die gesprek in die eerste plek die verheerliking van Christus (12) en as vrug daarvan die geloof deur die Heilige Gees en die saligheid van die wat glo. Die redding van die mens is dus vrug op die verheerliking van die Christus.

2. In hierdie gesprek moet ons ook weet met wie ons te make het. Is hy 'n vervreemde - dit wil sê van die kerk en evangelie ver- 
vreemd, of is hy 'n buite-kerklike, of is hy 'n post-Christelike wit heiden. Sinvolle vrae soos hoe, waar, wanneer, waarom en wat met betrekking tot sy huidige geestelike toestand kan besonder insiggewend wees.

3. Die vraag wat 'n gesprekvoerder moet uitmaak, is wat jy te sê het. Is jou boodskap of getuienis 'n boodskap wat spreek van:

Geloof: (2 Kor 5:15) - "sodat die wat lewe nie meer vir hulleself moet lewe nie, maar vir Hom wat vir hulle gesterf het en opgewek is". Wat vir ander bedelaars vertel waar die brood te vinde is.

Hoop: (Openb 21:5) - Ons leef vanuit die belofte van Openbaring 21:5. "Kyk Ek maak alle dinge nuut!" Die kerk moet self teken van hoop word en gestalte daaraan gee!

Liefde: (Joh 13:15, 16) - Die vertolking van dienskneg. "Ek is onder julle soos een wat dien." Uit die ruïnes van die Corpus Christianum verrys die Corpus Christi - juis in haar evangelisasie bely die kerk haar skuld oor die wyse waarop die kerk eerder wil oorheers as dien.

4. Die laaste saak wat jy moet uitmaak is: Hoe gaan jy dit sê? Gaan jy PROKLAMEER en getuig vanaf 'n afstand?

Gaan jy praat en luister: DIALOOG voer terwyl jy jou gespreksgenoot in die geheimenis of verborgenhede van God inlei?

Gaan jy met hom REDENEER en hom oortuig van die erns waarmee die GETUIENIS bejeën behoort te word?

\section{DIE TAAK VAN DIE KOMMUNIKASIEPROSES}

Die kommunikasie van die evangelie omvat vier aspekte wat nou met mekaar verweef is:

Getuienis,

Gemeenskap,

Diensbetoon en

Bevordering van die reg.

Saamgevat beteken dit dat die PROKLAMASIE in die gesprek sy REGMATIGE plek sal kry.

1. Proklamasie of kerugma dui in die Bybel die optrede aan van iemand wat as herout van die KURIOS, die verrese Heer, optree en namens Hom spreek terwyl ander luister. Hy vertel iets NUUTS, iets VREEMDS. 
2. In die GETUIENIS het ons in die Nuwe Testament te make met die aflê van hierdie getuienis voor mense oor: Wat sonder ons, maar inderdaad VIR ons gebeur het in die kruisiging en opstanding van Jesus Christus uit die dood.

Sowel die Proklamasie as die Getuienis vereis die dialoog, dit wil sê gespreksgeleentheid. Die PROKLAMASIE dra (openbaar) 'n gesaghebbende karakter. Dit kan nie aangepas word nie. Dit is soos dit is. Die dialoog openbaar 'n behoefte aan begrip. Dit vra om gehoor te word. Proklamasie en getuienis vra om gehoorsaamheid.

3. Wie die spanning tussen proklamasie en dialoog vernietig, vernietig sowel die proklamasie as die dialoog. Dan eindig die gesprek sonder dat iets sinvols plaasvind het. Die dialoog vra na proklamasie en getuienis, omdat dialoog alleen niks te sê het nie, niks wesenlik vir die mens kan bybring nie.

Die proklamasie en getuienis maak gebruik van die dialoog, ja vra daarvoor omdat die Woord so 'n kanaal verkry om sy einddoel, die mens wat vreemd staan teenoor die genade, te bereik. In die dialoog is daar die vertolking, die eie-maak van die Waarheid. Deur die dialoog vind die Waarheid sy weg na sy einddoel.

Ons moet in die verhouding wat daar tussen PROKLAMASIE, GETUIENIS en DIALOOG bestaan, leer om navolgers van Jesus Christus te word. Daar was by Jesus in sy omgang met mense 'n oorredende drang, 'n bindende erns, 'n ontwyfelbare aanspraak, maar tog ook 'n terughoudende respek vir die laaste beslissing. Die Here het niemand "gedwing" nie.

Om so 'n gesprek te voer, het ons die volgende nodig: waaksaamheid, liefde, innerlike voorbereiding deur gebed, Bybelstudie (kennis), selfkennis en veral geduld.

\section{DIE VOORBEREIDE GESPREK}

Die vraag ontstaan of mense met 'n voorbereide gesprek toegerus behoort te wees. Dit hang natuurlik daarvan af wat met "voorbereide" gesprek bedoel word. Vir die doel van hierdie stuk word met "voorbereid" die volgende bedoel:

1. 'n Riglyn van ' $n$ bepaalde invalshoek tot by 'n bepaalde bestemming. 
2. ' $n$ Bepaalde inhoud wat aangepas kan word na gelang van die persoon, omstandighede en situasie.

3. ' $n$ Bepaalde kennis en vermoë om 'n gesprek langs bepaalde riglyne te voer om 'n bepaalde doelwit te bereik.

4. Beslis nie 'n stuk papegaaiwerk wat woord vir woord bemeester en as sodanig aangebied word nie.

Die voordele van 'n voorbereide of skematiese gesprek waarborg

- dat omstandighede nie oorneem nie;

- die gespreksgenoot nie afdwaal en in nietige en onnodige detail verval nie;

- die doel bereik word en die boodskap "afgelewer" word.

\section{INHOUD VAN DIE GESPREK}

Soos reeds genoem, is die inhoud van die gesprek daarop gerig om die geheim van God se verlossende genade - dit wil sê Jesus Christus - te verkondig.

Dit gaan dus oor meer as net die vergiffenis van sonde ${ }^{13}$. In hierdie gesprek gaan dit oor

- die versoening van die sondaar deur die plaasbekledende lyding en offer van Jesus Christus;

- die mens as sondaar voor God;

- die vrede met God in en deur Jesus Christus;

- die vreugde van die verlossing;

- die nuwe lewe in Christus;

- die sekerheid van die verlossing;

- die priesterskap van die gelowige.

Uit hierdie gesprek word die lyne telkens getrek na die sentrum of kern waaroor dit alles gaan:

In watter verhouding jy voor en tot God staan.

- Dit wil sê 'n appèl word tot die mens gerig met wie daar in gesprek getree is. ${ }^{14}$

Alhoewel dit natuurlik baie belangrik is om te weet met wie jy te make het, wat jy te sê het en met watter doel jy dit sê, is die alles-oorheersende belangrike element van enige evangelisasiegesprek, die verheerliking van Jesus Christus ${ }^{12}$ (Joh 16:14). 
Dit is dan ook die gebod waarvan 1 Johannes 3:23 praat: "Ons moet in sy Seun Jesus Christus glo." Wie in die Seun van God glo, besit die getuienis in sy hart (1 Joh 5:10).

Die evangelisasiegesprek het dus sy oorsprong in die feit dat Jesus die Christus is en dat ons alleen deur Hom toegang het tot die Vader. Die evangelisasiegesprek het as doel die verheerliking van die Seun sodat die Vader in en deur Hom verheerlik sal word. Die evangelisasiegesprek het as vrug die heerlike vervulling: Elkeen wat in Hom glo, het die Ewige Lewe. Die kerk gehoorsaam hierdie opdrag, dus in die eerste plek is die doel nie die wen van siele of die uitbreiding van die getalle van die plaaslike gemeente nie - dit is sekondêr die vrug op die primêre doel: die verheerliking van die Seun van God, die Verlosser van die wêreld.

Wie anders optree en anders wil as wat die Woord oor hierdie saak leer, is nie besig om te dien nie, deur die Here te verheerlik nie, maar om sy eie belang te soek onder die dekmantel van gehoorsaamheid. Tydig klink die Woord ook hier: Alles wat nie uit die geloof is nie, is sonde.

Wat is dan die doel van ons gesprek oor die geloof? Dat die Seun verheerlik sal word en dat hulle wat Hom verheerlik deur in Hom te glo, saam met Hom verheerlik sal word.

\section{Verwysings}

1. Dr G Brillenburg-Wurth en ds WA Wiersenga, Het Evangelie in een ontkerstenende wêreld. JH Kok, NV Kampen, 1953, bl 7.

2. JD Douglas, Let the earth hear His voice. Int Congress on World Evangelism Lausanne, Switserland, 1974.

3. K Barth, KD Band IV, Zollikon, 1959.

4. Bakers Dictionary of Practical Theology. Ed R Tumbull. Bakerk Bookhouse, Grand Rapids, Michigan, bl 148.

5. Dr AC Barnard, Evangelistiek. NG Kerk Uitgewers, bl 97.

6. Dieselfde as 4, bl 173.

7. Dr AC Barnard, Evangelistiek, bl 89.

8. Idem, bl 95.

9. Idem, bl 96.

10. Dr J Verkuyl, Inleiding in die Evangelistiek. JH Kok, Kampen, 1978, bl 125.

11. Dr AC Bamard, Evangelistiek, bl 113.

12. Donald Guthrie, NT Theology. Intervarsity Press, p 531.

13. Dr AC Barnard, Evangelistiek, bl 117.

14. Idem, bl 117.

15. Sien verwysing 12 . 
Ander geraadpleegde werke:
(a) GE Sweazey, The church as Evangelist. Harper and Row, New York, 1978.
(b) Lloyd M Perry and J Strubhar, Evangelistic Preaching. Moody Press Chicago, 1979.
(c) RB Kuiper, God centred Evangelism. Hazel Watson and Viney, England, 1978.
(d) George Sweazey, Effective Evangelism. Harper and Row, 1976.
(e) JD Kennedy, Evangelism Explosion. Tyndale House Publishers, 1970/1977. 